\title{
ESTRATÉGIA DE LOCALIZAÇÃO E MODO DE ENTRADA DE ORGANIZAÇÃO DO SEGMENTO METALOMECÂNICO
}

Location strategy and entry model the Metalomechanical Segment

Ana Célia Bohn

E-mail: anaceliabohn@gmail.com

Mestra em Administração pela Universidade Regional de Blumenau; Doutoranda em Ciências

Contábeis e Administração na Universidade Regional de Blumenau; Professora no Centro Universitário-Católica de Santa Catarina em Jaraguá do Sul; Empresária na Empresa ACB

Assessoria e Treinamentos Empresariais.

Endereço para contato: Rua São Vicente, 220, Itoupava Norte, 89052-385, Blumenau, Santa

Catarina, Brasil.

https://orcid.org/0000-0001-8733-4668 


\section{Resumo}

O presente estudo, do tipo estudo de caso único (Yin, 2016), de natureza qualitativa, descritivo e bibliográfico, tem por objetivo compreender as motivações de internacionalização de uma organização multinacional do segmento metalomecânico, com matriz localizada no Brasil e subsidiárias em países distintos. Entre essas motivações, o estudo procura descrever as estratégias de localização e os modos de entrada (Cuervo-Cazurra \& Narula, 2015). Para o cumprimento do objetivo proposto foram necessárias pesquisas de ordem bibliográfica e eletrônica, em livros e sites específicos, bem como o aporte de dados secundários, com base no sítio oficial da organização, visita técnica guiada e entrevista semiestruturada de perguntas direcionadas a um gestor técnico, responsável pela área de internacionalização. A análise e discussão de resultados ocorreu pelo método de análise do conteúdo e discussão teórica. Observou-se que a organização objeto de estudo pulverizou seus negócios, expandindose em diversos segmentos de mercado nos cinco continentes em países desenvolvidos e em desenvolvimento. $O$ modo de entrada diferiu em cada situação, sendo consideradas as formas por aquisições, joint-ventures, escritórios em locais estratégicos ou instalação de fábricas novas, próprias (greenfields). A proporção do negócio agigantou-se desde os anos 2000 , demonstrando um crescimento médio anual de 15\%, a partir da internacionalização. As contribuições deste estudo enaltecem o desenvolvimento de empresas brasileiras no exterior, em termos de gestão organizacional e, enquanto contribuição científica, efetuou revisão de literatura de negócios internacionais e aproximou a academia da área empresarial, no que se refere à singularidade das estratégias de internacionalização.

Palavras-chave: Multinacionais. International Business. Estratégias de localização. Modo de entrada.

\section{Abstract}

The present study, of a single case study type (Yin, 2016), of a qualitative, descriptive and bibliographic nature, aims to understand the motivations for internationalization of a multinational organization in the metal-mechanic segment, with headquarters located in Brazil and subsidiaries in different countries. Among these motivations, the study seeks to describe the strategies of location and the entry model (Cuervo-Cazurra \& Narula, 2015). In order to fulfill the proposed objective, bibliographical and electronic research was required, in specific books and websites, as well as the provision of secondary data, based on the organization's official website, guided technical visit and semi-structured interview of questions directed to a technical manager, responsible for the internationalization area. The analysis and discussion of results occurred by the method of content analysis and theoretical discussion. It was observed that the organization under study dispersed its business, expanding in several market segments on the five continents in developed and developing countries. The entry model differed in each situation, considering the forms of acquisitions, joint ventures, offices in strategic locations or the installation of new, own factories (greenfields). The proportion of the business has increased since the 2000s, showing an average annual growth of $15 \%$, from internationalization. The contributions of this study highlight the development of Brazilian companies abroad, in terms of organizational management and, as a scientific contribution, carried out a review of international business literature and brought the academy closer to the business area, with regard to the uniqueness of internationalization strategies Keywords: Multinationals. International Business. Localization strategies. Entry model. 


\section{INTRODUÇÃO}

Nos estudos de negócios internacionais a primeira pergunta que surge é: por que existem empresas multinacionais (MNEs)? Essa pergunta passa a ter legitimidade no sentido de compreender o porquê as empresas decidem se internacionalizar ainda que enfrentem uma série de desvantagens, barreiras de entrada, riscos nos negócios internacionais-risco cambial, risco-país, risco intercultural e risco comercial (Cavulgil, Knight, \& Reisenberger, 2010). Além disso, vem a questão sobre o alto desempenho apesar de todos os riscos. Como isso é possível?

Considerando-se essa diversidade de ambientes $e$ as barreiras de entrada, organizações conseguem entrar no país destino, tornam-se competitivas e bem-sucedidas, ao que explicam Dunning e Lundan (2008), por conta das vantagens de propriedade, ativos tangíveis e intangíveis, ao que se conhece primariamente pelo paradigma eclético de Dunning (1988): posse, localização e internalização. Superando-se essas barreiras, operam no mercado de forma concentrada, demonstrando fontes de vantagens competitivas, apesar de que as MNEs incorrem em custos especiais (Hymer, 1976; Kindleberger, 1969). Nesse sentido, superar a "responsabilidade por estrangeirizar-se" (liability of foreignness) (Zaheer, 1995) requer transferência e vantagens competitivas específicas da empresa para uma subsidiária estrangeira (Dunning, 1988) ou, por utilização de vantagens específicas da subsidiária no país anfitrião (Kogut, 1991; Porter, 1990). Com isso, o resultado é o surgimento da empresa multinacional (MNE), tema ue contempla o objeto deste estudo de caso.

A partir dessas conjecturas, este artigo procura discutir teoricamente um estudo de caso único, de organização internacionalizada desde os anos 1970, e que se destaca na economia nacional e internacional no segmento metalomecânico, além de compreender as motivações, os modos de entrada e as estratégias utilizadas para a inserção em outros países.

Um aspecto importante que estudiosos da área de negócios internacionais procuram trazer em pauta é a globalização. Porém, esta representa o contexto no qual as multinacionais estão inseridas. A partir disso, discute-se a forma de atuação, a replicação ou não do modelorespeitando-se a aculturação, estratégias multinacionais, integração global e transnacional (Buckley, 2014; Cavulgil, et al., 2010; Hånell, Nordman, \& Tolstoy, 2019). Na sequência, as organizações que decidem se internacionalizar se preocupam com as estratégias do modo de entrada, se por exportação, por arranjos contratuais ou por investimento direto externo (IDE). O caminho trilhado por empresas que se tornaram multinacionais, em sua maioria, iniciou esse processo pela exportação, que é o caso em questão.

Nesse sentido, Coase (1937) chamou a atenção dos estudiosos que até a atualidade discutem o tema sobre: por que não usar a exportação como vantagem de propriedade em vez de usar o IDE? De acordo com seu parecer, se o fortalecimento da MNE for pela exportação, 
isso ocorre via mercado, seja o produtor vendendo para o distribuidor (importador), e este, por sua vez, para o consumidor. Porque, justifica o autor, se for feita pelo IDE, a transação sofre outro encaminhamento como se fosse uma substituição do mercado pela empresa multinacional. Há o contexto de organização da matriz e de suas subsidiárias para que a internacionalização aconteça por meio da própria empresa-sem atuação de externos. Em suma, sua indagação foi plausível e é amplamente discutida, tendo em vista a ineficiência e a imperfeição dos mercados. Destarte, demais motivações se concentram em modelos e motivações distintas (Herranz \& Machado, 2019).

Considerando a complexidade do tema, a gestão de contratos, os custos de transação e todos os aspectos que influenciam direta ou indiretamente as MNEs, elaborou-se a seguinte pergunta de pesquisa: quais foram os critérios que motivaram a internacionalização da empresa objeto de estudo, bem como suas estratégias de localização e respectivos modos de entrada? Para tanto, a próxima seção apresenta a base teórica que fundamenta a pesquisa, norteada pelos conceitos e evolução dos temas: multinacionais, estratégias de localização, modos de entrada, clusters e Distância Institucional (DI).

\section{BASE TÉORICA}

\subsection{MULTINACIONAIS}

A empresa multinacional ou transnacional representa o tipo de organização que tem relacionamento estrangeiro, com atividades de valor agregado, controladas, via investimento direto externo (IDE) ou, por investimento internacional em portfólio, atuante em um ou mais países no exterior (Dunning \& Lundan, 2008). Essa é uma definição aceita no meio acadêmico e empresarial, em agências de pesquisa, como a Organização de Cooperação e Desenvolvimento Econômico (OCDE), ou a UNCTAD's-Divisão de Investimento, Tecnologia e Desenvolvimento Empresarial (Dite).

Entre suas práticas, as MNEs contemplam atividades como o planejamento $e$ desenvolvimento (P\&D), compras, manufatura e marketing em qualquer parte do mundo, em locais economicamente viáveis. Além da sede, a multinacional típica possui uma rede mundial de subsidiárias e colabora com distintos fornecedores e parceiros independentes no exterior, também conhecidos como afiliados (Cavulgil et al., 2010). No entanto, estudiosos da área de negócios internacionais distinguem o universo das MNEs em empresas que realizam produção no país anfitrião, e as que possuem compromissos no exterior, como, por exemplo, a continuidade da estratégia gerencial e/ou organizativa integrada para suas operações no exterior e doméstica (Cavulgil et al., 2010; Dunning; Lundan, 2008). 
Em particular, os analistas de negócios apreciam distinguir entre as multinacionais que regem um grupo de multidomésticas, amplamente independentes das subsidiárias estrangeiras, cada uma das quais produz bens e serviços principalmente para o mercado local e aquelas que tratam seus afiliados como uma parte importante de uma região ou, a rede global, com atividades de criação de ativos e exploração de ativos. Para Dunning e Lundan (2008), a literatura investigada inclui vários critérios para avaliar o grau ou a intensidade das MNEs, ao que subscreveu sete classificações, descritas na Tabela 1:

Tabela 1

Critérios de avaliação do grau e intensidade das MNEs

1. Pelo número e porte de afiliadas estrangeiras ou empresas associadas que possuem ou exerce o controle.

2. Pelo número de países em que possuem ou, de alguma forma controlam o valor agregado de atividades como minas, plantações, fábricas, pontos de venda, bancos, escritórios e hotéis.

3. Pela proporção de seus ativos, receitas, rendimentos ou empregos globais representados por suas filiais estrangeiras.

4. Pelo grau em que sua gestão ou propriedade é internacionalizada.

5. Pela medida em que suas atividades de maior valor, por exemplo, pesquisa e desenvolvimento $(P \& D)$ são internacionalizadas. Essa medida destina-se a capturar a qualidade ou profundidade da produção estrangeira, e a contribuição das afiliadas estrangeiras para acessar ou gerar diretamente novos conhecimentos (spillover).

6. Pela extensão e o padrão das vantagens sistêmicas decorrentes da sua governança e influência sobre uma rede de atividades econômicas localizadas em diferentes países.

7. Pela mensuração da responsabilidade, criação e uso de instituições e bens, bem como pela tomada de decisão sobre questões financeiras e de marketing em que são devolvidas às filiais estrangeiras.

Nota. Adaptada de "Multinational Enterprises and the Global Economy," de J.H. Dunning e S.M. Lundan, 2008, (2nd ed.). Cheltenham, UK; Northampton, MA, USA: Edward Elgar.

De acordo com Cavulgil et al. (2010), para que uma organização atinja os critérios supracitados, o processo de internacionalização ocorre de formas distintas ou perpassa o caminho gradativo da exportação; depois, a globalização, com a integração de mercados, interconectividade; o comércio de bens e serviços, com a cadeia global de valores particionada, via IDE, com a detenção do controle ou por investimento internacional em portfólio. Nesse segundo não controla, mas investe em ações para alavancar dividendos ou, já nasce uma born global-que se refere a uma empresa exportadora de produtos de alto valor agregado, partindo-se de pequenas e médias empresas, tendo como característica principal o fato de não terem seguido um processo lento e gradual de envolvimento com o comércio internacional, operantes em nível global desde sua incipiência (Cavulgil et al., 2010; Rennie, 1993).

Em termos econômicos, a empresa multinacional é um veículo de crescimento de alavancagem para o país origem/sedee seu anfitrião (Buckley, 2002). Os negócios internacionais (International Business-IB) ocorrem de quatro formas distintas nessa alavancagem, sendo por meio de Knowledge-transferência de conhecimento; trade in products-comércio de 
produtos; trade in services-comércio de serviços elou direct investiments-Investimentos diretos (Cavulgil et al., 2010). Acerca disso, Buckley (2002) argumenta que, no passado, a pesquisa de IB conseguiu evoluir porque se concentrou em três grandes questões de pesquisa que resultaram de desenvolvimentos empíricos na economia mundial do pós-guerra e que serviram para unir o campo: como explicar os fluxos de investimento estrangeiro direto? Como explicar a existência, a estratégia e a organização de empresas multinacionais? Como entender e prever a internacionalização das empresas e o novo desenvolvimento da globalização? (Buckley, 2002). Porém, a agenda está paralisada porque nenhuma dessas questões importantes foram identificadas, tampouco respondidas pelos próprios estudiosos da área, que, posposto, levantaram outras questões, sem argumentações concisas.

Peng (2004) defende a ideia de que, para nutrir um distinto mercado intelectual em $I B$, são necessárias outras questões, no que concorda com o que implicitamente é tratado em Buckley (2002): o que determina o sucesso ou o fracasso de empresas internacionalizadas? Historicamente, as hipóteses de resposta foram se edificando ao longo do tempo, para o IB, com as raízes epistemológicas nos fundamentos econômicos, na teoria econômica de negócios internacionais. Foi esse o primeiro modelo desenhado por autores como Hymer (1976), com a teoria do poder de mercado e organização industrial; Vernon (1966), com a teoria do ciclo do produto; Aharoni (1966), que efetuou um elo entre as abordagem econômica e comportamental; Buckley e Casson (1976), com a teoria de internalização; Dunning (1988), como paradigma eclético (OLI), depois, em 2000 revisita o paradigma eclético, "40 anos"; Rugmann e Verbeke (2001) que discutiram os estudos até aquele período; Dunning e Lundan (2008), que melhoraram o modelo do paradigma eclético; Buckley (2014), que revisitou os princípios analíticos da teoria de internalização como uma teoria geral para as MNEs; Cuervo-Cazurra e Narula (2015), que ressignificaram o paradigma eclético de Dunning, com uma revisita de Ferreira, Serra, \& Reis (2011).

Destarte, esses são alguns exemplos de estudiosos em IB, a partir dos pressupostos da teoria econômica. Essa visão é importante porque está alicerçada no paradigma de negócios internacionais que se intercomunicam entre si, discutem resultados e fenômenos. Posteriormente, abre-se precedente para outra discussão, demonstrando que a abordagem econômica corria riscos de não ser dinâmica, porque seu debate se referia à racionalidade de decisões. Destarte, emerge a visão comportamental, com algumas questões levantadas por Vernon (1966) e solidificadas pelos estudos de Johanson e Vahlne $(1977,2009)$ e Vahlne e Johanson (2013). Nessa visão, o modelo de internacionalização está focado na aquisição gradual, integração e uso de conhecimento sobre mercados estrangeiros e operações. Aborda o conhecimento do mercado, as decisões e as atividades da MNEs. Posteriormente, os autores complementam uma nova visão do ambiente de negócios, retratado pelas networks (redes). Outras adições ao modelo foram: a criação da confiança e os aspectos relacionados ao conhecimento. Vahlne e Johanson (2013) apresentaram uma evolução do 
modelo, acrescentando que este se refere a uma alternativa ao paradigma eclético quanto às MNEs e ao IDE.

À luz dessa nova perspectiva, ocorreram mudanças nas relações comerciais e com vistas ao empreendedorismo, deixando de lado o enfoque na estrutura de produção. Sobre isso, na seção de "Distância Institucional", o assunto será retomado. Para a continuidade dos estudos e a compreensão das MNEs, a próxima seção discorre sobre as estratégias de localização.

\subsection{ESTRATÉGIAS DE LOCALIZAÇÃO E MODOS DE ENTRADA (ENTRY MODE)}

As estratégias para a internacionalização das empresas compreendem as estratégias de exportação, as estratégias contratuais e as estratégias de investimento (Cavulgil et al., 2010; Ning \& Sutherland, 2012; Root, 1994). A estratégia de entrada para os mercados internacionais confere às MNEs um plano abrangente, com o estabelecimento de objetivos, recursos e políticas que orientarão as operações comerciais internacionais de uma empresa durante um período futuro o tempo suficiente para alcançar um crescimento sustentável nos mercados mundiais (Root, 1994; Ning \& Sutherland, 2012). As estratégias de modo de entrada estão alicerçadas na perspectiva de um processo, que exigem decisões sobre: a escolha do mercado-alvo para um determinado bem de produção; os objetivos e metas para o mercado-alvo; a escolha de um modo de entrada para penetrar no país desejado; ter o plano de marketing específico para esse mercado; ter um sistema de controle para monitora o desempenho do mercado-alvo (Root, 1994).

Em termos modos de entrada internacionais, estes são possíveis por meio das exportações, pelo investimento direto externo (IDE) e, por arranjos contratuais. Nesses últimos, são possíveis os licenciamentos e as franchisings. Já o IDE representa a entrada por aquisição, greenfield, joint-venture ou filial integral (Ning \& Sutherland, 2012). O IDE ocorre de forma vertical e/ou horizontal, em quatro estratégias distintas: busca de mercados, busca de eficiência, busca de recursos e busca de ativos estratégicos (Cavulgil et al., 2010). O sentido do IDE incita a performance e inovação e a sustentabilidade do negócio ( $L i$, Strange, Ning, \& Sutherland, 2016).

Efetivamente, para que empresas estrangeiras consigam competir com as empresas domésticas dos países receptores devem aquelas ter algum tipo de vantagem competitiva. As três vantagens que precisam estar simultaneamente presentes para que a MNE prefira realizar investimento direto no exterior (face a outros modos de entrada) são: vantagens de posse, de localização e internalização (Ahsan \& Van Wyk; Dunning, 1988, 2000; Dunning \& Lundan, 2008, 2018). Há, ainda, a classificação de Dunning (1988), retomada por Ferreira et 
al. (2011), que distinguem quatro motivos: procura de mercado, de recursos, de eficiência e de recursos estratégicos.

Em sentido complementar, a entrada de uma organização em uma nova área geográfica pode ser explicada por um processo de legitimação de decisões de entrada ao longo do tempo (Arregle, Beamish, \& Hébert, 2009). As decisões anteriores legitimam as atuais e subsequentes ( Arregle et al., 2009), da mesma forma que a agregação pode ser vista como uma tentativa de minimizar a responsabilidade de estrangeiros encontrados no desenvolvimento de subsidiárias em uma nova área geográfica (Zaheer \& Manrakhan, 2001).

As empresas de fabricação e serviços podem entrar em mercados internacionais por vários motivos. Algumas delas estabelecem-se no exterior porque os mercados em casa se encontram-se estagnados, ou os mercados estrangeiros estão crescendo mais rápido. Outras, ainda, podem simplesmente seguir seus clientes domésticos que se internacionalizam, promovendo um motivo comum entre as empresas de serviços, como: publicidade, serviços de informática, engenharia e seguros (Root, 1994). Outros segmentos empresariais como indústrias oligopolistas seguem para o exterior no sentido de combinar com a entrada no mercado internacional de um rival doméstico (o efeito bandwagon), ou para contrariar empresas estrangeiras que penetram nos mercados domésticos (Root, 1994). Nesse sentido, há de se considerar as empresas que estão em busca de um maior volume de vendas, a fim de reduzir os custos unitários dos gastos gerais de fabricação e, assim, fortalecer sua competitividade tanto em casa quanto em países estrangeiros.

Ainda para Root (1994), no caso da empresa típica, a razão fundamental ou estratégica para entrar nos mercados estrangeiros se torna passível de algum tempo depois de seus primeiros empreendimentos tentativos nessa direção. As multinacionais podem limitar esse fardo, como conhecimento sobre especificidades da área pode ser compartilhado entre as subsidiárias na mesma área geográfica.

Por fim, um dos fatores que tangenciam a internacionalização de empresas é dado pelo modo de entrada das MNEs em outros países, no caso de afiliadas ou de subsidiárias. Por sua vez, o modo de entrada representa o elo entre os construtos multinacionais e clusters regionais (Rugman \& Verbeke, 2001). Assim, apresenta-se uma seção sobre clusters regionais.

\subsection{CLUSTERS REGIONAIS}

Conforme Petry (2016), a discussão original de distritos industriais tem suas referências no livro Principles of Economics, em 1890, de Alfred Marshall, que discutiu o fenômeno da aglomeração de indústrias especializadas em determinadas localidades, bem como as relações comerciais instituídas no ambiente local e os aspectos socioculturais. Na perspectiva de Marshall (1890), a aglomeração de indústrias está concentrada, fundamentalmente, na 
localização espacial de mercados, trabalhadores com habilidades especializadas, acesso aos insumos e serviços especializados e facilidade para spillovers tecnológicos.

Quanto ao surgimento dos clusters, estes foram motivados por políticas de desenvolvimento econômico baseadas em agrupamentos industriais. Por conseguinte, houve uma explosão de publicações sobre clusters industriais, clusters regionais, agrupamentos regionais, clusters industriais regionais, entre outras denominações (Enright, 2003).

Em tese, os estudiosos do assunto têm em comum a noção de que a aproximação em clusters se refere à proximidade geográfica entre as empresas inseridas em clusters, às quais emprestam alguma vantagem competitiva, embora a natureza específica das vantagens possa destoar de conceito a conceito (Bergman \& Feser, 1999; Petry, 2016). A proximidade geográfica facilita a formação e a transmissão de capital social, aumentando, dessa forma, a confiança e a capacidade de compartilhar informações vitais. E, ainda, o aumento da rivalidade faz com que as empresas aglomeradas vizinhas estimulem umas às outras para alcançar um maior nível de inovação e desempenho (Petry, 2016; Porter, 2009).

Os clusters estimulam a competitividade das empresas nas regiões e nações de três maneiras:

a) estar conectado a um cluster permite às empresas operar de forma mais produtiva. As empresas inseridas em um cluster têm melhor acesso aos meios necessários à realização de suas atividades, como tecnologia, informação, insumos, clientes e canais;

b) o acesso aos recursos do cluster melhorará a produtividade dos participantes e também sua capacidade de inovação;

c) um cluster existente pode fornecer uma base sólida para a criação de novas empresas, amenizando os efeitos das distâncias institucionais no modo de entrada das subsidiárias estrangeiras (Hospers \& Beugelsdijk, 2002; Porter, 2009; Petry, 2016).

Para tanto, a proximidade geográfica dos agentes econômicos que compõem os arranjos em clusters ajuda a melhorar a geração de conhecimento, diminuindo a Distância Institucional e contribuindo para melhor um desempenho das empresas (Petry, 2016). Assim, faz sentido compreender a Distância Institucional. 


\subsection{DISTÂNCIA INSTITUCIONAL}

A Distância Institucional (DI) refere-se ao nível de eficiência das subsidiárias no país anfitrião, dado que o ambiente estrangeiro é visto como o principal determinante da estrutura e do comportamento da empresa (Dimaggio, 1991; Dimaggio \& Powell, 1983; Petry, 2016; Scott, 2008). A DI representa a medida de similaridade ou dissimilaridade entre as instituições reguladoras, cognitivas e normativas entre os países de acolhimento e de origem da EMN (Kostova, 1999; Kostova \& Zaheer, 1999). Os efeitos da distância são definidos como os custos implícitos e sociais adicionais que as subsidiárias de EMNs enfrentam ao entrar em mercados estrangeiros, e desses custos seus homólogos nacionais estão isentos (Eden \& Miller, 2004; Petry, 2016; Zaheer, 1995, 2002), ou seja, os desafios, os quais precisam ser superados para a obtenção de resultados positivos, sejam eles, a DI geográfica ou psíquica. Nos estudos de Hånell et al. (2019) a DI é vista em consonância à responsabilidade quanto ao desenvolvimento de conhecimento estrangeiro e de redes. Os autores salientam que é mais desafiadora para os Born Globals (BGs) do que para os Born Regionals (BRs), e, por esse motivo, é provável que os BRs tenham um desempenho melhor que os $B G$. Nesse sentido, destacam uma "desvantagem global nascida" decorrente da falta de capacidade de adquirir conhecimento relevante do mercado externo e combater instituições do mercado externo (Hånell et al., 2019).

Sob a perspectiva comportamental, a Distância Institucional refere-se à distância psíquica, observada e considerada nos aspectos que tangenciam o Modelo de Uppsala, relacionada à soma dos fatores que influenciam o fluxo de informações entre os mercados. São exemplos a cultura do país anfitrião, a linguagem, as práticas de negócio, o desenvolvimento da indústria, aspectos políticos, entre outros (Johanson \& Vahlne, 1977, 2009). Os autores entendem que a distância psíquica representa a soma de fatores que impedem o fluxo de informação de um mercado a partir dos fatores apresentados.

$\mathrm{Na}$ tentativa de mensurar a distância cultural entre países, Kogut e Singh (1988) desenvolveram uma metodologia de medição para integrar quatro dimensões propostas por Hofstede (1980): aversão à incerteza; distância do poder; masculinidade/feminilidade; individualismo/coletivismo. Essas dimensões foram definidas a partir de uma investigação realizada com os gerentes da IBM, situados em 40 países, na década de 1970. Ghemawat (2001) desenvolveu outro método, no qual propôs a existência de várias distâncias, as quais exercem influência na atuação de firmas no exterior, como: distância cultural-diferenças de idiomas, religiões, raças, normas e valores sociais; distância geográfica-distância física, tamanho do país-anfitrião; Distância Institucional-heranças coloniais, sistemas políticos, instituições; e distância econômica-disponibilidade de recursos naturais, humanos e financeiros, poder aquisitivo, infraestrutura, acesso a insumos e conhecimentos. 
Os estudiosos da área trouxeram inúmeras contribuições sobre a implicação da Distância Institucional na escolha dos modos de entrada. Berry, Guillen, e Zhou (2010) discorreram sobre a distância econômica a qual se relaciona ao poder de compra dos consumidores e suas preferências, com a estabilidade macroeconômica do país foco de investimento e com o nível de abertura para o ingresso de capital estrangeiro. Em seu entendimento, há que se considerar, ainda, a distância financeira, política e administrativa.

Destarte, a distância de conhecimento, que diz respeito à capacidade de geração de conhecimento e de inovação, influencia diretamente a localização de um investimento e o modo de entrada. Esta por sua vez, é medida pelo número de patentes de um país e de artigos científicos per capita (Berry et al., 2010). Dessa maneira, as empresas que operam no exterior traduzem maior índice de sobrevivência no mercado nacional, pois emerge uma maior expertise proveniente da operação internacional (spillover) (Herranz \& Machado, 2019).

\section{METODOLOGIA}

Os procedimentos metodológicos adotados nesta pesquisa, de natureza qualitativa, que conforme Yin (2016) conferem ao estudo transparência, metodicidade, fidelidade às evidências e confiança dos dados, comportam um estudo de caso único, descrito em três partes distintas e complementares entre si. Em sua primeira etapa, realizou-se a pesquisa bibliográfica e descritiva. Ambas são procedimentos técnicos que visam a busca de fontes e informações em materiais existentes, no intuito de promover o entendimento e a evolução do tema em estudo (Richardson, 2012). Para tanto, o método de busca em termos bibliográficos consistiu na seleção de artigos científicos sobre o tema International Business, em alguns Journals específicos da área, bem como literatura e Biblioteca Digital Brasileira de Teses e Dissertações (BDTD).

Em sua segunda parte, contemplou o uso de dados secundários, obtidos por meio do sítio oficial da organização multinacional objeto de estudo, bem como dados adquiridos por meio de visita técnica guiada, realizada no segundo semestre de 2018 , na organização objeto de estudo, com a presença de gestor que proferiu palestra e visitação ao parque fabril. Finalmente, como terceira e última etapa de coleta de dados, a pesquisa contou com uma entrevista semiestruturada de perguntas norteadas pelos estudos de negócios internacionais em Cuervo-Cazurra e Narula (2015), Johanson e Vahlne (1977, 2009) e Root (1994) e direcionadas a um dos gestores técnicos ( $R \& D$ Coordinator) da organização, o qual se dispôs a conceder informações para a viabilização deste estudo, sendo aquele operante na área de internacionalização da organização.

Para a análise dos dados, de forma qualitativa, utilizou-se a técnica de análise de conteúdo e discussão teórica. Para Bardin (1979) 
"a análise de conteúdo é um conjunto de técnicas de análise das comunicações visando obter, através de procedimentos sistemáticos e objetivos de descrição do conteúdo das mensagens, indicadores.... que permitam inferir conhecimentos relativos às condições de produção/recepção (variáveis inferidas) dessas mensagens" (p. 31).

Optou-se por essa técnica tendo em vista a objetividade, a sistematização e a inferência (Richardson, 2012). A discussão teórica, por sua vez, aproxima a realidade quo dos processos empresariais da empresa objeto de estudo, em consonância aos estudos científicos consultados (Cuervo-Cazurra \& Narula, 2015; Herranz \& Machado, 2019; Root, 1994; Teixeira \& Flores, 2014), fortalecendo as descobertas e o transbordamento de conhecimento (spillover). Em termos de operacionalização, na intenção de convergir a análise do conteúdo à literatura de "IB", para o cumprimento dos objetivos propostos neste construto, estipulou-se a categorização de dados, a seguir, na Tabela 2:

Tabela 2

Categorias de Análise

\begin{tabular}{ll}
\hline \multicolumn{1}{c}{$\begin{array}{c}\text { CATEGORIAS } \\
\text { ANALÍTICAS }\end{array}$} & \multicolumn{1}{c}{ DEFINIÇÕES } \\
\hline & $\begin{array}{l}\text { Definição Constitutiva (DC): } \\
\text { A estratégia de entrada para os mercados internacionais confere às MNEs um plano } \\
\text { abrangente, com o estabelecimento de objetivos, recursos e políticas que orientarão } \\
\text { as operações comerciais internacionais de uma empresa durante um período futuro } \\
\text { o tempo suficiente para alcançar um crescimento sustentável nos mercados mundiais }\end{array}$ \\
$\begin{array}{ll}\text { Estratégias de } \\
\text { localização/ } \\
\text { Modo de Entra- } \\
\text { da } \\
\text { (Motivações) }\end{array}$ & $\begin{array}{l}\text { Definição Operacional (DO): } \\
\text { As estratégias de modo de entrada estão alicerçadas na perspectiva de um processo, } \\
\text { que exigem decisões sobre: a escolha do mercado-alvo para um determinado bem de } \\
\text { produção; os objetivos e metas para o mercado-alvo; a escolha de um modo de entrada } \\
\text { para penetrar no país desejado; ter o plano de marketing específico para esse mercado; } \\
\text { ter um sistema de controle para monitorar o desempenho do mercado-alvo (Herranz \& } \\
\text { Machado, 2019). }\end{array}$ \\
\hline
\end{tabular}

\section{Definição Constitutiva (DC):}

A aglomeração de indústrias está concentrada fundamentalmente na localização espacial de mercados, trabalhadores com habilidades especializadas, acesso aos insumos e serviços especializados e facilidade para spillovers tecnológicos (Herranz \& Machado, 2019; Marshall, 1890).

\section{Clusters}

\section{Definição Operacional (DO):}

Os clusters estimulam a competitividade das empresas de três maneiras: estar conectado a um cluster permite às empresas operar de forma mais produtiva. As empresas inseridas em um cluster têm melhor acesso aos meios necessários à realização de suas atividades, como tecnologia, informação, insumos, clientes e canais; o acesso aos recursos do cluster melhorará a produtividade dos participantes e também sua capacidade de inovação; um cluster existente pode fornecer uma base sólida para a criação de novas empresas, amenizando os efeitos das distâncias institucionais no modo de entrada das subsidiárias estrangeiras (Hospers \& Beugelsdijk, 2002; Porter, 2009). 
CATEGORIAS

ANALÍTICAS

\section{DEFINIÇÕES}

Definição Constitutiva (DC):

A Distância Institucional (DI) refere-se ao nível de eficiência das subsidiárias no país anfitrião, dado que o ambiente estrangeiro é visto como o principal determinante da estrutura e do comportamento da empresa (Dimaggio, 1991; Dimaggio \& Powell, 1983; Petry, 2016; Scott, 2008).

Distância Institucional (DI)

\section{Definição Operacional (DO):}

Sob a perspectiva comportamental, a Distância Institucional refere-se à distância psíquica, observada e considerada nos aspectos que tangenciam o Modelo de Uppsala, relacionada à soma dos fatores que influenciam o fluxo de informações entre os mercados. São exemplos: a cultura do país anfitrião, a linguagem, as práticas de negócio, o desenvolvimento da indústria, aspectos políticos, entre outros (Johanson \& Vahlne, 1977, 2009).

\section{ANÁLISE DOS RESULTADOS}

\subsection{DADOS DO CASO ESTUDADO: HISTÓRICO DE INTERNACIONALIZAÇÃO}

Com base em informações obtidas da organização objeto de estudo (site oficial e dados secundários), destaca-se que a WEG Equipamentos Elétricos S.A. foi fundada em 16 de setembro de 1961, na Cidade de Jaraguá do Sul, Santa Catarina, Brasil. A Empresa possui uma gama de produtos e serviços para aplicações industriais, de automação, além de motores, aerogeradores, transformadores, turbinas hidráulicas, painéis elétricos, drives e controls, tintas e vernizes industriais, tomadas e interruptores residenciais. Oferece serviços de engenharia de aplicação, projetos de automação, softwares aplicativos, start-up, recuperação de motores, geradores e transformadores, treinamentos e assistência técnica.

A estrutura de produtos e serviços é complementada por uma vasta rede de representantes, revendas e assistentes técnicos que abrangem todo o território brasileiro, além de revendas, distribuidores, fábricas e escritórios que dão suporte aos clientes em diversos países, com o maior parque fabril de motores elétricos do mundo (Lueders, 2018). A definição da marca WEG, que em alemão significa "caminho", veio da junção das iniciais de seus três fundadores: o eletricista Werner Ricardo Voigt, o administrador Eggon João da Silva e o mecânico Geraldo Werninghaus (Lueders, 2018).

Quatro anos após o início de suas atividades, a WEG instalou-se em um imóvel próprio, localizado na Rua Venâncio da Silva Porto, atual Parque Fabril I. No ano seguinte, possuía um quadro de 100 colaboradores. Mas, como a maior parte da mão de obra disponível na região estava na agricultura, sendo necessárias pessoas dispostas a adquirir novos conhecimentos, foi criado no ano de 1968 o Centro de Treinamento WEG. Nesse mesmo ano, os três fundadores partiram em viagem à Alemanha em busca de tecnologia e novos sócios 
alemães para o negócio. Chegando ao país, conseguiram informações técnicas valiosas que permitiram a criação de um novo motor que atendia rigorosamente às normas da Associação Brasileira de Normas Técnicas (ABNT) e da International Electrical Comission (IEC).

No ano de 1971, a WEG, completando dez anos de existência, tinha uma produção mensal de aproximadamente 7.000 motores. Nesse mesmo ano começou a se posicionar no mercado externo, realizando sua primeira venda a um país do exterior. O Paraguai foi o primeiro, em seguida outros países como Bolívia, Equador, Chile e Argentina. Em razão desse crescimento, em 1973 foi adquirido o terreno do novo parque fabril da WEG, conhecido como Parque Fabril II, onde se iniciaram as obras de construção da fábrica número dois da Eletromotores Jaraguá.

Produzindo inicialmente motores elétricos, a partir da década de 1980 visualizou-se a necessidade de diversificação de mercados. Foi então que nasceu a WEG Acionamentos, responsável pela fabricação de componentes eletroeletrônicos, informática e engenharia de aplicação para sistemas industriais; a WEG Máquinas, responsável por produzir máquinas elétricas girantes de grande porte, alternadores ou máquinas síncronas; a WEG Transformadores, produzindo equipamentos de distribuição de energia; a WEG Química, fabricando tintas e vernizes; e a WEG Automação, produzindo equipamentos para automação industrial. Visando à preservação e à busca de incentivos governamentais, surgiu a WEG Florestal, responsável pelos reflorestamentos e também pela extração e aproveitamento das madeiras utilizadas nas embalagens dos produtos.

No ano de 1989 ocorreu a primeira sucessão familiar da administração da empresa, por conta do Senhor Décio da Silva, um dos filhos do fundador Eggon João da Silva. Aquele, por sua vez, assumiu a presidência após exercer vários cargos administrativos dentro da organização e ter sido aluno da primeira turma do Centroweg. Durante a sua permanência no cargo, e empresa passou por um período de internacionalização e expansão. Nessa década, abriu a primeira filial nos Estados Unidos da América, a WEG Eletric Corporation; adquiriu uma empresa na Bélgica para atender à Europa; e chegou à Ásia com a abertura de uma filial no Japão. No final dos anos 1990 reforçou seu posicionamento na Europa, com a criação de filiais na Alemanha, Espanha, França, Inglaterra e Suécia, chegando à Oceania, com a abertura de uma filial na Austrália.

A partir dos anos 2000, a WEG adotou uma forte estratégia de conquista do mercado internacional, adquirindo empresas já estabelecidas em países alvo ou construindo atividades fabris nesses países, sendo alguns deles: México, Argentina, Portugal e China. Em 2007, a empresa foi dividida em quatro unidades de negócios: Motores, Energia, Automação e Tintas. Naquele mesmo ano, Harry Schmelzer Junior, o então diretor regional da Europa, foi eleito presidente executivo da empresa. Assim, a presidência deixou de ser familiar para ser conduzida por administradores, buscando a renovação e o crescimento contínuo. No ano seguinte, Décio da Silva foi eleito presidente do Conselho de Administração. 
Atualmente, a administração do Grupo WEG é exercida pelo Conselho de Administração, com funções deliberativas; pela Diretoria Executiva, com funções representativas e executivas; e pelo Conselho Fiscal. O Conselho de Administração é composto por oito membros, sendo: um presidente, um vice-presidente (independente) e seis membros, dois destes independentes. É de competência do Conselho de Administração avaliar formalmente os resultados de desempenho da companhia, do próprio Conselho, da Diretoria e, individualmente, dos membros de cada um desses órgãos. Para isso, o Conselho de Administração reúne-se sempre que necessário, ao menos trimestralmente, por convocação do seu Presidente.

A Diretoria Executiva é composta de 27 membros, sendo: um Diretor Presidente Executivo, um Diretor Vice-presidente, um Diretor de Relações com Investidores e demais Diretores. A Diretoria, dentro dos limites fixados em lei e pelo Estatuto Social da empresa, fica investida de amplos e gerais poderes de gestão que possibilitam a prática de todos os atos necessários ao regular o funcionamento da Companhia com vistas à consecução dos seus objetivos sociais. O Conselho Fiscal é permanente, composto de três membros efetivos e três suplentes, cabendo anualmente à Assembleia Geral Ordinária a eleição de seus membros.

Em 2010, a WEG passou a ter uma nova estrutura de organização. A Unidade de negócios Energia foi dividida formando-se então a Unidade de Negócios Energia, com a venda de geradores e a Unidade de Negócios Transmissão e Distribuição, com a venda de transformadores. No ano de 2010 continuou a expansão em novos negócios nacionais e internacionais, com a compra do Grupo Zest na África do Sul, o aumento de participação no Grupo Voltran no México, a aquisição da Instrutech em São Paulo e da Equisul em Florianópolis, ampliando ainda mais o portfólio de produtos.

No ano de 2011 foram adquiridas três novas filiais da Unidade Tintas: uma na Cidade de Mauá, em São Paulo, outra em Cabo de Santo Agostinho, Pernambuco, além da Pulverlux, na Argentina, possibilitando o aumento da produção dessa linha de produtos e a melhoria na logística de atendimento. Além destas, a WEG anunciou a aquisição da Empresa Watt Drive, na Áustria, especializada no desenvolvimento e fabricação de motorredutores, inversores de frequência e sistemas de acionamento.

Em 2012, anunciou sua entrada no mercado de energia limpa por meio da formação de uma Joint Venture com a Empresa espanhola M. Torres Olvega Industrial para a fabricação de aerogeradores no Brasil. No mês de novembro do mesmo ano, anunciou o término da Joint Venture. Em março de 2013, assinou o contrato de transferência de tecnologia para a produção de aerogeradores com a americana Northern Power Systems.

Além disso, efetuou aquisição da Empresa Injetel, fabricante de interruptores, tomadas e plugues, e adquiriu a empresa Hawker Siddeley Electric Africa, na África do Sul, a qual produz transformadores e subestações, buscando ampliar seu atendimento ao 
mercado mundial. Entre os anos 2012 e 2013 foram adquiridas ainda mais duas empresas brasileiras do ramo de tintas e vernizes, a Stardur e a Paumar S.A.

Em fevereiro de 2014, a linha de motorredutores oferecidos pela WEG no mercado europeu ficou mais completa com a aquisição do fabricante de motores elétricos e motorredutores Württembergishe Elektromotoren $\mathrm{GmbH}$, localizado na Cidade de Balingen, Alemanha. No mês de setembro de 2014 foi anunciada a compra da Empresa Efacec Energy Service Ltda., localizada no Estado de Pernambuco, que atua na manutenção de transformadores de força, motores, geradores, disjuntores e em serviços de engenharia de campo para diversos segmentos industriais de energia. Após, em outubro do mesmo ano, anunciou a aquisição da FTC Energy Group, Empresa que atua na fabricação e montagem de painéis elétricos para automação de processos com sede em Bogotá, na Colômbia. No início de novembro, anunciou a constituição de joint ventures com a Jelec Inc., Companhia norte-americana com sede em Houston, Texas. As joint ventures permitiram o fornecimento de pacotes integrados de engenharia de automação e produtos elétricos associados, atendendo à demanda crescente do mercado de exploração e produção de petróleo e gás natural, no Brasil e ao redor do mundo.

No ano de 2015 foi anunciada a aquisição do negócio de fabricação de transformadores de alta tensão, minissubestações, disjuntores moldados e serviços correlatos, pertencentes à Empresa TSS Transformers, fabricante com sede em Heidelberg, África do Sul. Em maio do mesmo ano, anunciou a aquisição da Empresa Suntec, fabricante de transformadores a óleo e secos, com sede em Medellín, Colômbia. Em setembro desse mesmo ano anunciou a aquisição da Autrial S.L., na Espanha, fabricante de painéis elétricos para equipamentos e instalações industriais. Ainda em 2015, no mês de outubro, anunciou a nova fábrica de tintas em Mauá, SP. E, em novembro, anunciou a nova fábrica em Portugal (Santo Tirso) para a produção de motores de baixa tensão (até 3,5 toneladas).

Em março de 2016 a Weg anunciou a aquisição da Bluffton Motor Works, nos EUA, companhia esta especializada na manufatura de motores elétricos fracionários comerciais ou rolled steel até $5 \mathrm{CVs}$. Em abril do mesmo ano, inaugurou sua nova fábrica em Rugão, na China. Em outubro de 2016 anunciou a aquisição do negócio de turbinas eólicas utiliyscale da Northern Power Systems, Empresa sediada nos EUA que projeta, desenvolve e fabrica aerogeradores e é pioneira e uma das líderes tecnológicas em aerogeradores de imãs permanentes e sem caixa de multiplicadora de velocidade. Com esse novo empreendimento, tornou-se a única proprietária da carteira de patentes, ativos, know-how e materiais afins, incluindo todos os desenhos, projetos, especificações e software utilizados em conexão com - projeto e manutenção de geradores com mais de 1,5 megawatts de capacidade nominal (utility-scale). Em dezembro de 2016 a Weg anuncia a aquisição do controle da TGM Indústria e Comércio de Turbinas e Transmissão Ltda., localizada em Sertãozinho, São Paulo, líder 
brasileira no fornecimento de soluções e equipamentos para acionamentos de geradores de energia elétrica.

Na atualidade, a OrganizaçãoWEG é responsável pelo abastecimento de grande parte do mercado brasileiro de motores elétricos, líder no setor na América Latina e encontra-se entre os cinco maiores fabricantes mundiais de motores. Para que seu caminho de liderança se perpetue, a Empresa desenvolveu o planejamento estratégico WEG 2020-Continuous Growth, que tem por objetivo atingir 20 bilhões de reais em faturamento, dobrando o número de colaboradores até o ano de 2020. Caracterizada por um modelo vertical de gestão, a WEG é capaz de fabricar a maior parte dos componentes necessários para a confecção de seus produtos. Para isso, conta com departamentos de fundição, estamparia de chapas, injeção de alumínio, injeção de plásticos, usinagem, trefilação e esmaltação.

No Brasil, a produção se concentra em 12 parques fabris distribuídos pelas cidades de Jaraguá do Sul, SC, Guaramirim, SC, Blumenau, SC, Joaçaba, SC, Itajaí, SC, São Bernardo do Campo, SP, Manaus, AM, Gravataí, RS, Hortolândia, SP, Linhares, ES e Mauá, SP. No exterior, a produção se concentra em parques fabris localizados na Argentina, México, China, Portugal, Estados Unidos, Alemanha, África do Sul, Índia e Áustria.

Até 2017 a WEG era composta por cinco unidades de negócio, sendo cada uma delas responsável por uma gama de produtos: Motores (WMO), Energia (WEN), Automação (WAU), Transmissão e Distribuição (WTD) e Tintas (WTI). Essas cinco unidades possuem sede em Santa Catarina e contam com extensões no Brasil e no exterior. Enquanto estrutura de pessoal, empregam cerca de 29.860 colaboradores, entre os quais estão os contratados pela empresa, temporários, terceiros e estagiários, que estão alocados nos cinco continentes. Além destes, a empresa conta com uma ampla rede de assistentes técnicos espalhados por todo o Brasil e também distribuidores presentes em mais de 135 países, aptos a fornecerem todo o suporte necessário de vendas e manutenção de produtos. Do total de colaboradores, cerca de $80 \%$ deles estão situados no Brasil.

Enquanto segmentação de negócios, como principais focos, têm-se: Fabricantes de Máquinas e Equipamentos (OEM), Açúcar e Etanol, Mineração, Papel e Celulose, Petróleo e Gás, Naval, Alimentos e Bebidas, Construção Civil, Energia, Infraestrutura e Siderurgia. Quanto aos produtos fabricados e os serviços prestados por cada unidade de negócios, têmse: motores, automação e energia.

Por fim, com base nos dados abstraídos por meio de dados secundários, fornecidos pela própria empresa, em termos de material institucional e sítio oficial e depoimento de colaboradores, apresenta-sem, na sequência, as informações obtidas por meio da visita técnica guiada e entrevista. 


\subsection{VISITA TÉCNICA GUIADA E ENTREVISTA}

A visita técnica guiada, ocorrida nas dependências do Parque Fabril da Weg Drives \& Controls-Automation contou com a participação de mestrandos e doutorandos dos Cursos de Administração e Ciências Contábeis da Fundação Universidade Regional de Blumenau (FURB) e professores. A palestra inicial foi conduzida por um gestor responsável pela área de internacionalização, com mais de 30 anos de empresa, intitulado colaborador " $A$ ".

Nessa visita, as informações que se seguiram corresponderam com os dados secundários, obtidos por meio do sítio oficial da empresa, no que se refere à liderança em vendas de máquinas e motores. Destacou " $A$ " que a empresa se encontra em período de maturidade com relação aos produtos de alto valor e tecnologia empregada (sendo, esta, própria). Com relação à atuação em mercados internacionais, confirmou que, em primeiro momento, ocorreram as exportações, a partir dos anos 1970. Após isso, nos anos 1990, houve a expansão, com a instalação de filiais em outros países. Ao todo, afirmou "A" que há 37 fábricas espalhadas nos cinco continentes. Estas, por sua vez, foram oriundas de aquisições ou de greenfields (fábricas próprias). Em termos de distribuidores, está presente em 20 países. A partir de 2008 houve o fortalecimento das unidades fabris nos mercados internacionais.

Como primeira fase de sua internacionalização, a organização objeto de estudo teve, desde 1961 até 1969 o foco total no Brasil, tanto em produção quanto em vendas. Nesse período desenvolveu o CentroWeg para a formação técnica de mão de obra especializada e para a institucionalização da cultura empresarial.

Apontou "A" os anos 1970 como a segunda fase, com a incipiência das exportações para os países Paraguai, Equador e Uruguai, bem como a participação em feiras internacionais. Atrelou esse fato à aproximação de seus proprietários com contatos nesses países por meio de sua etnia alemã.

Na terceira fase, intensificaram-se as exportações, por meio de network-rede de relacionamentos, com distribuidores e representantes em novos mercados. Ampliação da Rede de ATs (Rede de assistentes técnicos-pessoas elou empresas treinadas, capacitadas ou habilitadas para executar serviços ou reparos em produtos que a empresa fabrica), departamento comercial, certificações de produtos, participação em feiras e aprimoramento da língua inglesa para colaboradores envolvidos nos negócios internacionais (IB).

Em sua quarta fase, nos anos 1990, as filiais somaram um total de 26. A primeira filial comercial foi fundada em 1991, nos EUA, estrategicamente alocada para atuação no mercado externo. Iniciou-se nesse período a COMEX-Weg Exportadora (trading) e as expatriações de colaboradores brasileiros para suprir o capital intelectual e transferência de conhecimento aos locais de estabelecimento fora do País. 
$\mathrm{Na}$ quinta fase, começou a instalação de fábricas, já nos anos 2000, como um processo de globalização e a acepção do multiculturalismo. A partir de 2010, a alavancagem foi significativa, com a sexta fase, por meio de aquisições e fusões. Apontou "A" que, em 2011, ocorreu a primeira greenfield, na Índia e, posteriormente, em 2015, na China.

Após a obtenção dessas informações, por meio da explanação de "A", todos os visitantes foram conduzidos ao Parque Fabril de "Drives" para entender um pouco sobre o processo produtivo e a logística dos materiais e produtos, que ocorrem de forma similar nas fábricas do exterior.

Para consolidar e ressignificar o conteúdo da visita guiada, contando com a participação do Colaborador "B", sendo este Gestor de R\&D Coordinator, o qual atua no acompanhamento técnico das fábricas e filiais do exterior, apresenta-se a seguir o conteúdo oriundo de entrevista semiestruturada, norteada pelos estudos em negócios internacionais (IB), na forma de categoria de dados, descritos na seção de procedimentos metodológicos e assentados nesta seção, na Tabela 3:

Figura 2

Resultados de entrevista

\begin{tabular}{|c|c|c|}
\hline $\begin{array}{l}\text { Categoria de } \\
\text { Análise }\end{array}$ & $\begin{array}{c}\text { Descrição Constitutiva } \\
\text { (DC) }\end{array}$ & A prática da MNE Objeto de Estudo (DO) \\
\hline $\begin{array}{l}\text { Estratégias de } \\
\text { localização/ } \\
\text { Modo de Entrada } \\
\text { (Motivação) }\end{array}$ & $\begin{array}{l}\text { A estratégia de entra- } \\
\text { da para os mercados } \\
\text { internacionais confere } \\
\text { às MNEs um plano } \\
\text { abrangente, com o } \\
\text { estabelecimento de } \\
\text { objetivos, recursos e } \\
\text { políticas que orientarão } \\
\text { as operações comerciais } \\
\text { internacionais de uma } \\
\text { empresa durante um } \\
\text { período futuro o tempo } \\
\text { suficiente para alcançar } \\
\text { um crescimento sus- } \\
\text { tentável nos mercados } \\
\text { mundiais } \\
\text { (Root, 1994). }\end{array}$ & $\begin{array}{l}\text { Contexto: "Hoje a WEG exporta para mais de } 135 \text { países e } \\
\text { tem fábricas estabelecidas em } 12 \text { países. O modelo inicial } \\
\text { de entrada foi através de Distribuidores. Em seguida, foram } \\
\text { feitas aquisições, como, por exemplo, na Argentina, México, } \\
\text { China, Áustria, Alemanha, Espanha e Colômbia. Finalmente } \\
\text { a entrada foi através de greenfiled, que são os exemplos do } \\
\text { México, Índia e China." } \\
\text { Motivação para a atuação no exterior: "Aumento dos } \\
\text { negócios da WEG [. . .] busca de tecnologia, conhecimento } \\
\text { de grandes clientes internacionais, aquisição de experiên- } \\
\text { cia internacional e reconhecimento da marca WEG a nível } \\
\text { internacional." } \\
\text { Decisão de local: "Totalmente estratégicas pois estão loca- } \\
\text { lizadas em locais de fácil acesso aos grandes usuários do } \\
\text { produto WEG." } \\
\text { Alianças: "Sim, possuímos alianças com entidades que admi- } \\
\text { nistram produtos que a WEG participa, tais como CEMEP, } \\
\text { ANIE, CESI, UL, CSA, SABS e outras." } \\
\text { Subsidiárias: "O estabelecimento de filiais no exterior foi } \\
\text { gerado primeiramente pela vontade (estratégia) de fazer } \\
\text { crescer os negócios da WEG, uma vez que o Brasil teria sua } \\
\text { limitação. Em alguns mercados o motivo principal foi base- } \\
\text { ado na oportunidade; em outros, na necessidade de estar } \\
\text { mais próximo do cliente." }\end{array}$ \\
\hline
\end{tabular}




\begin{tabular}{|c|c|c|}
\hline $\begin{array}{l}\text { Categoria de } \\
\text { Análise }\end{array}$ & $\begin{array}{l}\text { Descrição Constitutiva } \\
\text { (DC) }\end{array}$ & A prática da MNE Objeto de Estudo (DO) \\
\hline Clusters & $\begin{array}{l}\text { A aglomeração de in- } \\
\text { dústrias está concentra- } \\
\text { da fundamentalmente } \\
\text { na localização espacial } \\
\text { de mercados, trabalha- } \\
\text { dores com habilidades } \\
\text { especializadas, acesso } \\
\text { aos insumos e serviços } \\
\text { especializados e faci- } \\
\text { lidade para spillovers } \\
\text { tecnológicos (Herranz } \\
\text { \& Machado, 2019; Mar- } \\
\text { shall, 1890). }\end{array}$ & $\begin{array}{l}\text { Configuração: "Não são clusters. São sedes próprias com } \\
\text { ligação direta com a matriz no Brasil." }\end{array}$ \\
\hline $\begin{array}{l}\text { Distância Institu- } \\
\text { cional (DI) } \\
\text { sob a perspectiva } \\
\text { comportamental: } \\
\text { "Distância psíqui- } \\
\text { ca" }\end{array}$ & $\begin{array}{l}\text { A Distância Institucio- } \\
\text { nal (DI) refere-se ao } \\
\text { nível de eficiência das } \\
\text { subsidiárias no país } \\
\text { anfitrião, dado que o } \\
\text { ambiente estrangeiro } \\
\text { é visto como o princi- } \\
\text { pal determinante da } \\
\text { estrutura e do com- } \\
\text { portamento da em- } \\
\text { presa (Dimaggio, 199l; } \\
\text { Dimaggio \& Powell, } \\
\text { 1983; Scott, 2008; Petry, } \\
2016 \text { ). } \\
\text { Sob a perspectiva } \\
\text { comportamental, a } \\
\text { distância institucional } \\
\text { refere-se à distância } \\
\text { psíquica. São exem- } \\
\text { plos: a cultura do país } \\
\text { anfitrião, a linguagem, } \\
\text { as práticas de negó- } \\
\text { cio, o desenvolvimento } \\
\text { da indústria, aspectos } \\
\text { políticos, entre outros } \\
\text { (Johanson \& Vahlne, } \\
1977,2009 \text { ). }\end{array}$ & $\begin{array}{l}\text { Desafios: "Conhecimento da legislação e requisitos locais de } \\
\text { cada país, impostos locais, idioma, requisitos técnicos e des- } \\
\text { conhecimento do how to do business locally, usos e costumes } \\
\text { locais." } \\
\text { Transferência de Conhecimento: "Através do contato direto } \\
\text { entre as áreas técnicas e de engenharia no que se refere a } \\
\text { projeto e fabricação. Com relação aos aspectos administra- } \\
\text { tivos, existe uma troca efetiva de pessoas de todos os níveis } \\
\text { entre a matriz e as filiais e entre as filiais e a matriz." } \\
\text { Retenção do Conhecimento: "Criação de normas e proce- } \\
\text { dimentos internos para a realização dos trabalhos que hoje } \\
\text { está concentrada numa biblioteca chamada WEGnology em } \\
\text { que todos os colaboradores têm acesso. Para reter o capital } \\
\text { intelectual a WEG investe em um pacote de benefícios e } \\
\text { programa motivacional." } \\
\text { Transbordamento (Spillover): ".., toda tecnologia de uma } \\
\text { filial adquirida ou estabelecida é colocada numa mesma } \\
\text { base com a matriz para discutir e implementar possíveis } \\
\text { melhorias no sistema técnico e de produção. Os recursos } \\
\text { humanos locais também têm tido um papel importante na } \\
\text { melhoria da organização como um todo." } \\
\text { E } \\
\text { "... viagens, períodos de estágio, seminários técnicos, parti- } \\
\text { cipação em feiras e eventos, criação de procedimentos com } \\
\text { participação de pessoas da filial e da matriz." }\end{array}$ \\
\hline
\end{tabular}

Acerca dos dados obtidos nesta entrevista, na visita técnica guiada e conteúdo documental (dados secundários-site oficial e materiais disponibilizados), na seção seguinte apresentam-se a discussão dos resultados e a inferência teórica ao caso analisado.

\subsection{DISCUSSÃO TEÓRICA DOS RESULTADOS}

Discutir os resultados de um estudo de caso único, dessa magnitude, a partir dos pressupostos teóricos de IB, com ênfase na abordagem comportamental-Uppsala Model 
(Johanson \& Vahlne, 1977, 2009), foi uma tarefa árdua, no sentido de não menosprezar as nuances e detalhes contidos no processo que levou essa Organização a se tornar multinacional.

Com vistas ao atingimento do objetivo de pesquisa que buscou saber quais foram os critérios que motivaram a internacionalização da empresa objeto de estudo, bem como suas estratégias de localização e respectivos modos de entrada, infere-se em primeira análise a abordagem de Dunning e Lundan (2008), disposta na Tabela l, sobre os "Critérios de avaliação do grau e intensidade das MNEs", ao que se percebeu que a WEG apresentou suas atividades centradas em pesquisa e desenvolvimento ( $P \& D$ ), fortemente presentes no âmbito da internacionalização. Essa medida destina-se a capturar a qualidade ou profundidade da produção estrangeira; e à contribuição das afiliadas estrangeiras para acessar ou gerar diretamente novos conhecimentos (spillover). Para tanto, a observação oriunda desse objetivo se referiu às oportunidades e acolhimento do país destino.

Este estudo de caso vem ao encontro das questões levantadas por Vernon (1966) e solidificadas pelos estudos de Johanson e Vahlne $(1977,2009)$ e Vahlne e Johanson (2013), os quais, nessa visão, explicam que o modelo de internacionalização está focado na aquisição gradual, integração e uso de conhecimento sobre mercados estrangeiros e operações. Esse fato é confirmado na palestra proferida pelo colaborador "A", na visita guiada, tanto quanto reforçado na entrevista concedida por " $\mathrm{B}$ " e disponibilizado nos dados secundários, os quais apontaram o processo primário de exportação, nos anos 1970, e a expansão inicial em 1990, a partir dos EUA, seguidos de distribuidores, escritórios comerciais até a iniciação das aquisições e greenfields.

Vahlne e Johanson (2013) abordam a importância do conhecimento de mercado, as decisões e as atividades da MNEs. Posteriormente, os autores complementam uma nova visão do ambiente de negócios, retratada pelas networks (redes). Essas redes foram estabelecidas pela organização em estudo desde o início dos anos 1970, no processo primário de internacionalização, via exportações. Vahlne e Johanson apresentaram uma evolução do modelo, acrescentando que este se referia a uma alternativa ao paradigma eclético OLI (Dunning, 1988) no que se refere às MNEs e ao IDE. A WEG utilizou-se, em tese, de IDE, porém, sem a perspicácia de seus sociofundadores (networks), ainda que, com capital próprio a ser investido, os contratos não teriam sido consolidados. Esse foi o relato obtido no momento da visita técnica, com explanação do colaborador " $A$ ".

Conforme a entrevista com o colaborador "B", a motivação para atuar no exterior visou à expansão e ao aumento dos negócios, em busca de tecnologia, conhecimento, experiência e reconhecimento da marca, fato procedente, tendo em vista o desempenho positivo nos balanços anuais da organização, disponíveis no sítio oficial desta, em que se considera um percentual de $15 \%$ a.a. de incremento, desde os anos 1990, a partir do processo de internacionalização. A procedência dessa informação é validada a partir do construto de Root (1994), o qual afirma que as empresas de fabricação e serviços podem entrar 
em mercados internacionais por vários motivos. Algumas delas se estabelecem no exterior porque os mercados em casa se encontram estagnados ou os mercados estrangeiros estão crescendo mais rápido. E, o internamento do processo de internacionalização ocorreu por fases, e a entrada, de formas distintas.

As estratégias de localização (entry mode) e as reais motivações que conceberam à Empresa WEG o título de líder no setor de motores elétricos na América Latina e estar entre os cinco maiores fabricantes mundiais de motores, sumariamente dizem respeito às estratégias de gestão organizacional que concernem a um caminho de liderança de mercado, com o desenvolvimento do planejamento estratégico WEG 2020-Continuous Growth, que tem por objetivo atingir 20 bilhões de reais em faturamento, dobrando o número de colaboradores até o ano de 2020. Esse modelo de gestão verticalizada segue orientado pelo Conselho Diretor e Governança Corporativa que decidem onde e como proceder com sua expansão, aproveitando as oportunidades em países tanto desenvolvidos quanto em desenvolvimento.

Com relação ao fato de estar estabelecida em clusters regionais, de acordo com a entrevista concedida pelo colaborador "B", isso não ocorreu, mas, em observância aos dados secundários, a WEG procurou estabelecer-se para atender a demandas locais, fornecendo produtos para clientes dentro de mercados domésticos. Portanto que, em casos específicos a serem estudados com maior profundidade, é possível encontrar a organização entre a categorização de aglomerados, visto que, "a partir dos anos 2000, a WEG adotou uma forte estratégia de conquista do mercado internacional, adquirindo empresas já estabelecidas em países-alvo ou construindo atividades fabris nesses países, sendo alguns deles: México, Argentina, Portugal e China." (Entrevista de "B") (Informação verbal).

Sobre a distância institucional, com vistas à distância psíquica, em Johanson e Vahlne (2009) ficou evidente que a organização prima pela excelência na qualidade de produtos e processos, e, por isso, aposta na transferência do conhecimento entre matriz e subsidiárias (spillover), apesar de todos os desafios enfrentados, conforme depoimento de "B" sobre ter "conhecimento da legislação e requisitos locais de cada país, impostos locais, idioma, requisitos técnicos e desconhecimento do 'how to do business locally', usos e costumes locais." (Informação verbal). Nesse sentido, salienta-se a distância de conhecimento, a qual diz respeito à capacidade de geração de conhecimento e de inovação, que influencia diretamente a localização de um investimento e o modo de entrada (Berry et al., 2010).

Diante de todas essas considerações, depreende-se que a abordagem comportamental, oriunda do Modelo de Uppsala, prevalece neste estudo, seja pelo capital intelectual (gerenciamento), seja pela transferência do conhecimento, transbordamento (spillover), distância cultural e enfrentamentos de ordem psíquica em relação ao país anfitrião com o país origem (Herranz \& Machado, 2019). A Organização confere aos seus gestores a confiança e a credibilidade em promover e alicerçar a sua cultura, ainda que admita a multiculturalidade a partir de sua inserção internacional. 


\section{CONSIDERAÇÕES FINAIS}

O objetivo proposto neste artigo foi o de compreender as motivações de internacionalização de uma organização do segmento metalomecânico, originalmente brasileira, e discutir teoricamente os aspectos que emergiram da pesquisa. Para tanto, observou-se que os critérios adotados foram diversificados, ao encontro das oportunidades país/destino; e uniformes com a estratégia da organização, referente ao projeto de expansão internacional (Cuervo-Cazurra \& Narula, 2015; Ferreira, et al., 2011).

Uma das contribuições deste estudo demonstrou o desenvolvimento de empresas brasileiras no exterior, em termos de gestão organizacional e; enquanto contribuição científica, efetuou uma revisão de literatura consubstanciada na área de negócios internacionais, no sentido de promover a aproximação da academia com a atuação empresarial, haja vista as singularidades das estratégias de internacionalização.

Quando da observação do memorial descritivo do processo de internacionalização da organização objeto de estudo, com o uso de motivações distintas, observou-se que há um encontro da literatura com as práticas organizacionais no que se refere à distância institucional, principal desafio encontrado pelas multinacionais. Foi possível vislumbrar o desenvolvimento continuado de uma empresa brasileira no exterior, suas estratégias, modos distintos de entrada e resultados positivos das respectivas inserções. Porém, destaca-se que nem todas as decisões foram acertadas (conforme depoimento de "A"), e que se julgou como aprendizado.

Tendo em vista a discussão teórica a partir dos resultados obtidos com o estudo de caso, descreve-se como limitação de pesquisa o fato de não se ter acesso às subsidiárias estrangeiras, para a compreensão do contexto no qual cada uma das fábricas está inserida. Nesse sentido, seria possível entender a presença ou não de subsidiárias em clusters, já que, conforme Petry (2016), "o grande desafio das multinacionais é o de superar as distâncias, sejam elas econômicas, culturais, institucionais, ou meramente geográficas." Assim, há a relevância da aproximação das multinacionais em clusters, pelos interesses, alianças ou o próprio fortalecimento do aglomerado, pela amplitude do conhecimento e seu transbordamento (spillover). Ainda que no depoimento em " $B$ " não haja aproximação por cluster, este, por sua vez, admitiu alianças com entidades para o fortalecimento dos produtos WEG. Então, cabe aqui uma investigação mais aprofundada, em momento oportuno, por concessão da Organização e conveniência/acessibilidade dos pesquisadores.

Quanto a estudos futuros, sugere-se o aprofundamento do referencial teórico em Journals, do tipo bibliométrico, para a convalidação de pareceres distintos de autores e para o refinamento do suporte de pesquisas vindouras a este trabalho, bem como estudos 
nas subsidiárias WEG do exterior, a fim de entender o contexto local, não apenas os dados obtidos por meio da matriz, com a finalidade de compreender melhor a distância psíquica existente e os maiores desafios enfrentados tanto nos países em desenvolvimento quanto em países desenvolvidos.

Por fim, este estudo permitiu tanto o entendimento das principais correntes teóricas em IB quanto foi possível compreender o processo de internacionalização de uma organização destaque no Brasil e com presença solidificada no exterior.

\section{REFERÊNCIAS}

Aharoni, Y. (1966). The foreign investment decision process. In P. J. Buckley, M. Ahsan, M., \& J. Van Wyk (Eds.), (2018), Going Past Entry Mode: Examining Foreign Operation Mode Changes at the Strategic Business Unit Level. Journal of Managerial Issues, 30(1), 28-34.

Arregle, J. L., Beamish, P. W., \& Hébert, L. (2009). The regional dimension of MNEs' foreign subsidiary localization. Journal of International Business Studies, 4O(1), 86-107. Recuperado de http://doi.org/10.1057/jibs.2008.67

Bardin, L. (1979). Análise de conteúdo. Lisboa: Edições 70.

Bergman, E. M., \& Feser, E. J. (1999). Industrial and regional clusters: Concepts and comparative applications. The Web Book of Regional Science. Morgantown: Regional Research Institute: West Virginia University.

Berry, H., Guillen, M., \& Zhou, N. (2010). An Institutional Approach to Cross-National Distance. Journal of International Business Studies, 41(9), 1460-1480.

Buckley, P. J., \& Casson, M. (1976). The future of the multinational entrerprise. London and Basingstoke: The Macmillan Press.

Buckley, P. J. (2014). Forty years of internalisation theory and the multinational enterprise. Multinational Business Review, 22(3), 227-245.

Buckley, P. J. (2002). Is the international business research agenda running out of steam? Journal of International Business Studies, 33(2), 365-373.

Cavulgil, S. T., Knight, G., \& Riesenberger, J. R. (2010). Negócios Internacionais: Estratégia, gestão e novas realidades. São Paulo: Pearson Prentice Hall.

Coase, R. H. (1937). The nature of the firm. Economica, 4(16), 386-405. 
Cuervo-Cazurra, A., \& Narula, R. (2015). A set of motives to unite them all? Revisiting the principles and typology of internatization motives. Multinational Business Review, 23, 2-14. Recuperado de http://doi.org/10.1108/MBR-03-2015-0010

Dimaggio, P. J. (1991). Constructing an organizational field as a professional project: U.S. art museums, 1920-1940. In W. Powell \& P. J. Dimaggio (Eds.), The new institutionalism in organizational analysis (pp. 267-292). Chicago, IL: University of Chicago Press.

Dimaggio, P. J., \& Powell, W. W. (1983). The Iron Cage Revisited: Institutional Isomorphism and Collective Rationality in Organizational Fields. American Sociological Review, 48(2), 147-160.

Dunning, J. H., \& Lundan, S. M. (2008). Multinational Enterprises and the Global Economy, second edition. Cheltenham, UK; Northampton, MA, USA: Edward Elgar.

Dunning, J. H. (2000). The ecletic paradigm as an envelope for economic and business theories of MNE activity. International Business Review, 9, 163-190.

Dunning, J. H. (1988). The ecletic paradigm of international production: A restatement and some possible extensions. Journal of International Business Studies, 1-31.

Eden, L., \& Miller, S. R. (2004). Distance Matters: Liability of Foreignness, Institutional Distance and Ownership Strategy. In M. Hitt \& J. Cheng (Eds.), Theories of the Multinational Enterprise: Diversity, Complexity and Relevance (Advances in International Management (pp. 187-222). Amsterdam, Netherlands: Elsevier.

Enright, M. J. (2003). Regional clusters: What we know and what we should know. In J. Bröcker, D. Dohse, \& R. Soltwedel (Eds.), Innovation clusters and interregional competition (pp. 99-129). Berlin, Heidelberg: Springer.

Ferreira, M. A. S. P. V., Serra, F. R., \& Reis, N. M. R. dos (2011). Motivações para a internacionalização e modos de entrada nos mercados externos. Revista lbero-americana de Estratégia, 10(1), 29-54.

Ghemawat, P. (2001). Distance still matters: The hard reality of global expansion. Harvard Business Review, 79(8), 137-145.

Hånell, S. M., Nordman, E. R., \& Tolstoy, D. (2019). Born Globals or Born Regionals? A Study of 32 Early Internationalizing SMEs. International Business in a VUCA World: The Changing Role of States and Firms (Progress in International Business Research), 14, 289-308. 
Herranz, A., \& Machado, H. P. V. (2019). Motivadores da Internacionalização de Pequenas Empresas de Software: Um estudo multi casos nos contextos brasileiro e espanhol. Revista Eletrônica de Ciência Administrativa, 18(2), 261-280.

Hofstede, G. (1980). Culture's consequences: International differences in work-related values. Beverly Hills: Sage Publications.

Hospers, G., \& Beugelsdijk, S. (2002). Regional cluster policies: Learning by comparing? Kyklos, 55(3), 381-402.

Hymer, S. H. (1976). The international operations of national firms: A study of direct investment. Cambridge, MA: MIT Press.

Johanson, J., \& Vahlne, J. (1977). The Internalization Process of The Firm-A Model of Knowledge Development and Increasing Foreign Market Commitments. Journal of International Business Studies, 8(1), 23-32.

Johanson, J., \& Vahlne, J. (1990). The mechanisms of internationalization, International Marketing Review, 7(4), 11-24.

Johanson, J., \& Vahlne, J. (2009). The Uppsala internationalization process model revisited: From liability of foreignness to liability of outsidership. Journal of International Business Studies, 40, 1411-1431.

Kindleberger, C. (1969). American Business Abroad. New Haven, CT: Yale University Press.

Kogut, B. (1991). Country capabilities and the permeability of borders. Strategic Management Journal, 12, 33-47.

Kogut, B., \& Singh, H. (1988). The effect of national culture on the choice of entry mode. Journal of International Business Studies, 19, 411-432.

Kostova, T., \& Zaheer, S. (1999). Organizational legitimacy under conditions of complexity: The case of the multinational enterprise. Academy of Management review, 24(1), 64-81.

Kostova, T. (1999). Transnational transfer of strategic organizational practices: A contextual perspective. Academy of Management review, 24(2), 308-324.

Li, J., Strange, R., Ning, L., \& Sutherland, D. (2016). Outward foreign direct investment and domestic innovation performance: Evidence from China. International Business Review, 25(5), 1010-1019. 
Lueders, A. (2018). Estruturar, condição para crescer: De eletromotores Jaraguá a WEG S.A. ( $1^{a}$ ed.). Jaraguá do Sul: Impressul.

Marshall, A. (1890). Principles of economics: An introductory volume. Retrieved from https:// www.marxists.org/reference/subject/economics/marshall/

Ning, L., \& Sutherland, D. (2012). Internationalization of China's private sector MNEs: An analysis of the motivations for foreign affiliate formation. Thunderbird International Business Review, 54(2), 169-182.

Peng, M. W. (2004). Identifying the big question in international business research. Journal of International Business Studies, 35, 99-108. doi:10.1057/palgrave.jibs. 8400077

Petry, J. F. (2016). Distância institucional e o desempenho das subsidiárias estrangeiras: Os efeitos moderadores dos recursos de clusters e modos de entrada (Tese de doutorado, Universidade Regional de Blumenau). Retirado de http://www.bc.furb.br/docs/ TE/2016/362361_1_l.pdf

Porter, M. E. (2009). Competição. Rio de Janeiro: Campus.

Porter, M. E. (1990). The competitive advantage of nations. New York: Free Press.

Rennie, M. (1993). Global Competitiveness: Born Global. McKinsey Quarterly, 4, 45-52.

Richardson, R. J. (2012). Pesquisa Social: Métodos e técnicas. (3 ${ }^{a}$ Rev. ed. e ampl.). São Paulo: Atlas.

Root, F. R. (1994). Entry strategies for international markets. Nova York: Lexington Books.

Rugman, A. M., \& Verbeke, A. (2001). Location, competitiveness and the multinational enterprise. In A. M. Rugman (Ed.), Oxford handbook of international business. (2nd ed.). Oxford: Oxford University Press.

Scott, W. R. (2008). Approaching adulthood: The maturing of institutional theory. Theory and Society, 37(5), 427-442.

Teixeira, A. P. P., \& Flores, F. S. (2014). O modelo de Internacionalização de Uppsala sob a ótica da Visão Baseada em Recursos (RBV). Revista Científica do Alto Vale do Itajaí, $3(3), 1-12$. 
Vahlne, J., \& Johanson, J. (2013). The Uppsala model on evolution of the multinational business enterprise-from internalization to coordination of networks. International Marketing Review, 30(3), 189-210.

Vernon, R. (1966). International investment and international trade in the product cycle. The quarterly journal of economics, 190-207.

Yin, R. K. (2016). Pesquisa qualitativa: Do início ao fim. Porto Alegre: Penso.

WEG. (2019). Retirado de https://www.weg.net/institutional/BR/pt/history

Zaheer, S. (1995). Overcoming the liability of foreignness. Academy of Management Journal, 38, 341-363.

Zaheer, S., \& Manrakhan S. (2001). Concentration and Dispersion in Global Industries: Remote Electronic Access and the Location of Economic Activities. Journal of International Business Studies, 32(4), 667-686.

Zaheer, S. (2002). The liability of foreignness, redux: A commentary. Journal of International Management, 8(3), 351-358.

\section{Como citar este artigo:}

\section{ABNT}

BOHN, Ana Célia. Estratégia de localização e modo de entrada de organização do Segmento Metalomecânico. RACE, Revista de Administração, Contabilidade e Economia, Joaçaba: Editora Unoesc, v. 19, n. 2, p. 361-388, maio/ago. 2020. Disponível em: http://editora.unoesc.edu.br/index.php/race. Acesso em: dia/mês/ano.

\section{APA}

BOHN, A. C. (2020). Estratégia de localização e modo de entrada de organização do Segmento Metalomecânico. RACE, Revista de Administração, Contabilidade e Economia, 19(2), 361-388. Recuperado de http://editora.unoesc.edu.br/index.php/race 